\title{
Modeling Heat, Water Vapor, and Carbon Dioxide Flux Distribution Inside Canopies Using Turbulent Transport Theories
}

\author{
Gabriel Katul* and Mario Siqueira
}

\begin{abstract}
This study reports recent developments in mulitlayer turbulent transport methods to compute distributions of strengths of scalar sources and sinks $S_{\mathrm{c}}$ as well as turbulent fluxes $F_{\mathrm{c}}$ within the plantatmosphere continuum. In particular, we focus on the so-called "inverse methods" that estimate $S_{\mathrm{c}}$ from measured mean scalar concentration (or temperature) distribution within the canopy without resorting to any ecophysiologically based input. These approaches are able to reproduce measured turbulent fluxes above and within the canopy without relying on gradient diffusion formulation. Comparison between measured and modeled sensible heat flux vertical attenuation within the canopy suggests that all three methods provided comparable root-mean squared error (RMSE) $\left(\sim 50 \mathrm{~W} \mathrm{~m}^{-2}\right)$. Furthermore, correcting for local atmospheric stability significantly improved the agreement between model calculations and measurements. Comparisons between measured and modeled land surface fluxes of sensible heat, latent heat, and $\mathrm{CO}_{2}$ above the canopy are conducted using wavelet spectral methods applied to a wide range of temporal scales (30 min-2 yr). This study is the first to rigorously assess the performance of several inverse methods for such a broad range of time scales. We found that the three inverse modeled flux spectra bound the measured one. Hence, spectral agreement among the three models provides the necessary confidence in calculated fluxes and scalar sources. Conversely, large disagreement between the inverse models "flags" large uncertainties at those particular time scales.
\end{abstract}

$\mathrm{O}$ NE OF THE MAJOR CHALLENGES in quantifying mass (water vapor, $\mathrm{CO}_{2}$ ) and energy exchanges between the land surface and the atmosphere is that vegetation is a biologically active source or sink of matter and energy and can modify its microclimate through complex turbulent exchange processes. How vegetated surfaces interact with their local microclimate, which in turn influences the exchange of $\mathrm{CO}_{2}$, water vapor, and heat with the atmosphere has received considerable attention. In fact, variants on this question form key research themes in the Carbon Cycle Science Plan (Sarmiento and Wofsy, 1999) and the Water Cycle Science Plan (Hornberger et al., 2001) of the United States Global Change Research Program (USGCRP). This is not surprising given the modulating role of the biosphere on global atmospheric $\mathrm{CO}_{2}$ concentration (Wofsy et al., 1993 ) and on the general spatial and temporal characteristics of the water cycle (Chen et al., 2001; Maurer et al., 2001). A direct outcome of such attention is the emergence and exponential growth of four continental flux-monitoring networks: EuroFlux, AmeriFlux, AsiaFlux, and OzFlux (Valentini et al., 2000; Kaiser, 1997),

G. Katul, Nicholas School of the Environment and Earth Sciences and Department of Civil and Environmental Engineering, Box 90328, Duke University, Durham, NC 27708-0328 and M. Siqueira, Department of Civil and Environmental Engineering, Duke University, Durham, NC 27708. Received 28 Nov. 2001. *Corresponding author (Gaby@duke.edu).

Published in Vadose Zone Journal 1:58-67 (2002). all participating in a world-wide flux monitoring initiative known as FluxNet (Baldocchi et al., 2001).

Within FluxNet, many of the flux measurements are conducted within the canopy sublayer of tall forests, thereby prohibiting the use of single-layer (or big leaf) approaches to link turbulent fluxes with their microclimate. Here we consider mulitlayer theories (Finnigan and Raupach, 1987; Raupach, 1988) which explicitly consider the nonuniform vertical structure of the canopy and can resolve the subsequent feedbacks of such nonuniformity on the microclimate via complex turbulent transfer processes. The objective is to present and evaluate recent advances in methods that estimate scalar source-sink distribution within the canopy using multilayer transport theories and over a broad range of time scales, ranging from minutes to years.

Multilayer theories are commonly classified as either "forward" or "inverse" depending on the types of measurements performed (Raupach, 1989a,b). In forward approaches, the source strength and location is specified such that knowledge of the turbulent transport mechanics permits the estimation of downwind mean scalar concentration and flux distribution. The inverse problem utilizes measured mean scalar concentration distribution downwind from the source in concert with knowledge of the turbulent transport mechanics to infer the source-sink strength distribution. The interest in inverse models is driven, in part, by the fact that mean concentration can be more easily measured (or monitored) within the canopy than can the actual sources and sinks, or fluxes. Furthermore, these methods do not require any ecological or ecophysiological input, making them suitable for long-term source-sink calculations. To date, no one study evaluated inverse models over a broad range of time scales ranging from hour to years.

While we focus on inferring sources and sinks within the canopy volume, we stress that both their interpretation and controls cannot be divorced from their counterpart in the vadose zone. For example, water vapor sources in the canopy volume are strongly impacted by the hydraulics of root water uptake; forest floor respiration is intimately linked to root and microbial respiration, which in turn are influenced by the amount of $\mathrm{C}$ sequestered by the leaves. Hence, it is constructive to probe some analogies between the laminar fluid flow commonly encountered in the vadose zone and turbulent flows inside canopies before presenting the inverse models for the canopy volume.

\section{Canopy Turbulence vs. Vadose Zone Transport}

Biological sources (or sinks) and fluxes are directly related by a scalar continuity equation (in the vertical

Abbreviations: ASL, atmospheric surface layer; EUL, Eulerian closure "inverse" model; HEL, hybrid Eulerian-Lagrangian model; LNF, localized near field theory; ODE, ordinary differential equation. 
dimension), whether be it in the canopy atmosphere or the vadose zone (see Fig. 1), which is given by

$$
\frac{\partial \bar{C}}{\partial t}+\frac{\partial F_{\mathrm{c}}}{\partial z}=S_{\mathrm{c}}
$$

where $\bar{C}$ is the mean concentration of a scalar entity $C$ (i.e., $\mathrm{H}_{2} \mathrm{O}, \mathrm{CO}_{2}$, and air temperature $T_{\mathrm{a}}$ ), $F_{\mathrm{c}}$ is the mean vertical flux of the scalar entity (e.g., $F_{\mathrm{CO} 2}, F_{\mathrm{H} 2 \mathrm{O}}$, and $F_{\mathrm{T}}$ are the $\mathrm{CO}_{2}, \mathrm{H}_{2} \mathrm{O}$, and sensible heat fluxes at height $z$, respectively), and $S_{\mathrm{c}}$ is the mean vegetation source strength (i.e., sink implies $S_{\mathrm{c}}<0$ ) at time $t$ and height $z$ above (or below in the case of vadose zone) the ground surface.

For canopy flows, all mean quantities are subject to both time and horizontal averaging as described by Raupach and Shaw (1982). The scalar continuity equation (Eq. [1]) can be used to compute one of the unknowns $\left(\bar{C}, F_{\mathrm{c}}, S_{\mathrm{c}}\right)$, provided additional information is available on the remaining two variables.

Early attempts to estimate biological sources and sinks $S_{\text {c }}$ from mean concentration $\bar{C}$ relied on the socalled "K-theory", which relates $F_{\mathrm{c}}$ to the vertical gradient of $\bar{C}$ using some effective eddy diffusivity $K_{\mathrm{m}}(z)$. Combining this approximation with Eq. [1] for stationary conditions leads to

$$
S_{\mathrm{c}}=-\frac{\partial}{\partial z}\left[K_{\mathrm{m}}(z) \frac{\partial \bar{C}}{\partial z}\right]
$$

The right-hand side of Eq. [2] depends only on $\bar{C}$ and $K_{\mathrm{m}}$.

The formulation in Eq. [2] is common to many contemporary vadose zone transport problems involving biologically active sources or sinks. For example, estimating root water uptake $\left(S_{\mathrm{H} 2 \mathrm{O}}\right)$, production or consumption of methane gas $\left(S_{\mathrm{CH} 4}\right)$ in the soil pore space, and root and microbial production of $\mathrm{CO}_{2}\left(S_{\mathrm{CO} 2}\right)$ for the root-soil components all lead to nonlinear diffusionlike equations (e.g., Jury et al., 1991):

$$
\begin{aligned}
& S_{\mathrm{H}_{2} \mathrm{O}}=-\frac{\partial \theta}{\partial t}-\frac{\partial}{\partial z}\left[K(\theta) \frac{\partial \psi(\theta)}{\partial z}-1\right] \\
& S_{\mathrm{CH}_{4}}=-\frac{\partial C_{\mathrm{CH}_{4}}}{\partial t}-\frac{\partial}{\partial z}\left[D_{\mathrm{CH}_{4}} \frac{\partial C_{\mathrm{CH}_{4}}}{\partial z}\right] \\
& S_{\mathrm{CO}_{2}}=-\frac{\partial C_{\mathrm{CO}_{2}}}{\partial t}-\frac{\partial}{\partial z}\left[D_{\mathrm{CO}_{2}} \frac{\partial C_{\mathrm{CO}_{2}}}{\partial z}\right]
\end{aligned}
$$

where $\theta$ is the soil moisture content; $K(\theta)$ and $\psi(\theta)$ are the soil hydraulic conductivity and retention functions, respectively; $D_{\xi}$ is the soil gas diffusivity, which depends on the molecular diffusivity of species $\xi$ as well as the soil physical properties (e.g., air-filled porosity, temperature); and $C_{\xi}$ is the pore-space concentration of species $\xi$. In Eq. [3], a laminar flow approximation permits the usage of Darcy's and Fick's Laws to estimate fluxes from gradients of the state variables, thereby reducing the estimation of $S_{\mathrm{c}}$ to solving diffusion equations analogous to Eq. [2], provided concentration or soil moisture content are measured in depth and time.

Within the atmospheric surface layer, (ASL, see Fig. 1),
Atmospheric Surface Layer $\sim 3$ - 5 H

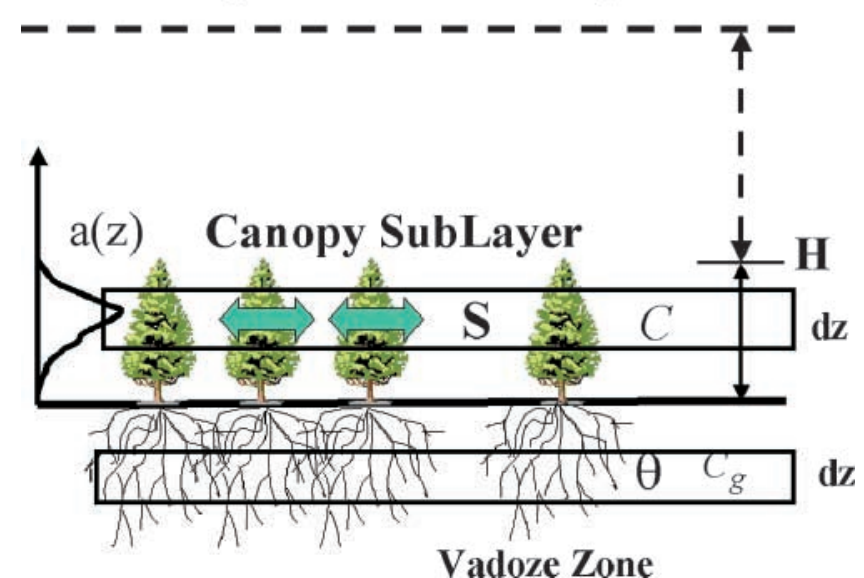

Fig. 1. Schematic of the canopy sublayer (CSL) domain bounded by the vadose zone and the atmospheric surface layer (ASL), where $h$ is the canopy height. An elemental volume of thickness $\mathrm{d} z$ sufficiently large to include biological sources and sinks are shown in the canopy sublayer and the vadose zone. Inverse problems in both domains estimate such biological sources and sinks from the depthtime measured concentration, temperature, or soil moisture content.

successes of surface layer similarity theory (e.g., Brutsaert, 1982, p. 209-230) to predict $K_{\mathrm{m}}$ from the velocity statistics, given by

$$
K_{\mathrm{m}}=\frac{k\left(z-d_{\mathrm{c}}\right) u_{*}}{\phi_{\mathrm{c}}(z / L)}
$$

profoundly influenced the search for an analogous formulation inside canopies, where $k$ is the von Karman constant, $d_{\mathrm{c}}$ is the scalar zero-plane displacement height, $u_{*}$ is the friction velocity, $\phi_{\mathrm{c}}$ is a stability correction function, and $L$ is the Obukhov length (e.g., Brutsaert, 1982, p. 209-230). With such a $K_{\mathrm{m}}$ model, the analogies between Eq. [2] and [3] are evident: both equations are inferring biological mass production (or consumption) within a porous media (soil or foliage) by continuous diffusion transfer.

However, by the 1970s and early 1980s, it was recognized that the canopy sublayer (Fig. 1) possesses unique attributes prohibiting the use of "gradient-diffusion" models or K-theory that appears to be reasonable in the vadose zone and for ASL transport. A local imbalance between production and dissipation terms in the scalar flux budget can lead to the so-called "counter-gradient" fluxes-or negative diffusivities (Finnigan, 2000). Limitations of K-theory are well recognized (e.g., Raupach, 1988; Wilson, 1989) and documented by several field experiments (e.g., Denmead and Bradley, 1985; Katul et al., 1997b) and laboratory studies (e.g., Coppin et al., 1986). Raupach and Tom (1981) provided a detailed survey of the early field and laboratory experiments that led to a better understanding of the inadequacies of K-theory. In the last $15 \mathrm{yr}$, two basic approaches have emerged to circumvent the limitations of K-theory in canopy flow inverse models: Lagrangian dispersion models (e.g., localized near field theory) and higher-order Eulerian closure models. This study evaluates the performance of such methods to reproduce land-atmosphere fluxes of heat, 
water vapor, and $\mathrm{CO}_{2}$ for time scales ranging from 30 min to multiple years.

\section{Inverse Models of Canopy Flow}

In this section, a brief review of three inverse methods, including Eulerian, Lagrangian, and hybrid schemes is provided for completeness.

\section{The Localized Near Field Theory}

The localized near field theory (LNF), proposed more than a decade ago, has gained popularity among the inverse methods. It was successfully applied over a wide range of vegetation types, including artificial vegetation in wind tunnels, rice canopies, and pine forests (Raupach et al., 1992; Denmead and Raupach, 1993; Denmead, 1995; McNaughton and Van den Hurk, 1995; Van den Hurk and McNaughton, 1995; Katul et al., 1997b; Massman and Weil, 1999; Leuning, 2000; Leuning et al., 2000; Warland and Thurtell, 2000; Katul et al., 2001b). The basic premise of LNF is that the difference in the mean scalar concentration $\bar{C}$ at any height $\mathrm{z}$ and a reference value $\bar{C}_{\mathrm{R}}$ measured above the canopy at $z_{\mathrm{R}}\left(z_{\mathrm{R}}>\right.$ $h)$ is calculated by a superposition of near field $\left(C_{\mathrm{n}}\right)$ and far field $\left(C_{\mathrm{f}}\right)$ contributions:

$$
\bar{C}(z)-\bar{C}_{\mathrm{R}}=C_{\mathrm{n}}(z)+C_{\mathrm{f}}(z)
$$

Raupach (1989a,b) showed that the near field contribution is computed via a kernel function:

$$
C_{\mathrm{n}}(z)=\int_{0}^{\infty} \frac{S_{\mathrm{c}}\left(S_{0}\right)}{\sigma_{\mathrm{w}}\left(S_{0}\right)}\left\{k_{\mathrm{n}}\left[\frac{z-s_{0}}{\sigma_{\mathrm{w}}\left(s_{0}\right) T_{\mathrm{L}}\left(s_{0}\right)}\right]+k_{\mathrm{n}}\left[\frac{z+s_{0}}{\sigma_{\mathrm{w}}\left(s_{0}\right) T_{\mathrm{L}}\left(s_{0}\right)}\right]\right\} d s_{0}
$$

where $s_{0}$ is a dummy variable, $\sigma_{\mathrm{w}}$ is the vertical velocity standard deviation, and $T_{\mathrm{L}}$ is a lagrangian time scale. An analytical approximation for the kernel function $k_{\mathrm{n}}$ was also derived by Raupach (1989a) and is given by:

$$
k_{\mathrm{n}}(\xi)=-0.39894 \ln \left[1-e^{-|\xi|}\right]-0.15623 e^{-|\xi|}
$$

The far field contribution is calculated using results from the near field and a gradient-diffusion relationship and is given by:

$$
C_{\mathrm{f}}(z)=\bar{C}_{\mathrm{R}}-C_{\mathrm{n}}\left(z_{\mathrm{R}}\right)+\int_{z}^{z_{\mathrm{R}}} \frac{F_{\mathrm{c}}(z)}{\sigma_{\mathrm{w}}^{2}(z) T_{\mathrm{L}}(z)} d z
$$

and the Lagrangian time scale can be estimated by:

$$
\frac{T_{\mathrm{L}}(z) u_{*}}{h}=\beta
$$

where, $\beta(\sim 0.1)$ is a constant (see also Raupach et al., $1996)$, and $u_{*}$ is the friction velodity.

With these formulations for $C_{\mathrm{n}}$ and $C_{\mathrm{f}}$, and with direct concentration measurements within the canopy, it is possible to estimate the sources and sinks via Eq. [2]. One practical limitation to applying the above formulation is that the measured $\bar{C}$ is "infected" with sampling and instrumentation errors. Such errors are likely to introduce spurious and large oscillations in the computed $S_{\mathrm{c}}$. To avoid numerical instability when computing $S_{\mathrm{c}}$, redundant concentration measurements are necessary (i.e., the number of concentration measurements $n$ must exceed the number of source layers $m$ ).

As shown in Raupach (1989a), such redundancy transforms the inverse problem into a regression problem given by

$$
\sum_{k=1}^{m} A_{\mathrm{jk}} S_{\mathrm{k}}=B_{\mathrm{j}} \quad(j=1, \ldots, m)
$$

where:

$$
\begin{aligned}
A_{\mathrm{jk}} & =\sum_{\mathrm{i}=1}^{n} D_{\mathrm{ij}} \Delta z_{\mathrm{j}} D_{\mathrm{ik}} \Delta z_{\mathrm{k}} \\
B_{\mathrm{j}} & =\sum_{l=1}^{n}\left(\overline{C_{l}}-\overline{C_{\mathrm{R}}}\right) D_{\mathrm{lj}} \Delta z_{\mathrm{j}}
\end{aligned}
$$

Once $A_{\mathrm{jk}}$ and $B_{\mathrm{j}}$ are determined from the measured concentration and modeled dispersion matrix $\left(D_{\mathrm{ij}}\right)$, the estimation of the source strength can be readily achieved. Details on the generation of $D_{\mathrm{ij}}$ can be found in Raupach (1989a,b). The LNF approach does not allow for non-zero vertical velocity skewness, strong inhomogeneity in vertical source strength variation, or mean horizontal velocity variation within the canopy. These limitations can be relaxed in practice if one invokes a second-order Eulerian closure "inverse" model (EUL), as proposed by Katul and Albertson (1999) and described next.

\section{Eulerian Methods}

Upon applying time and horizontal averaging, the steady-state scalar conservation equation for planar homogeneous and high Reynolds and Peclet number flows (neglecting molecular diffusion) can be written as (Finnigan, 1985; Raupach, 1988):

$$
\frac{\partial \bar{C}}{\partial t}=0=-\frac{\partial \overline{w^{\prime} C^{\prime}}}{\partial z}+S_{\mathrm{c}}
$$

where primes denote fluctuations from time averages and $w$ is the vertical velocity. Equation [5] is identical to Eq. [1] if $F_{\mathrm{c}}=\overline{w^{\prime} C^{\prime}}$ is the scalar vertical flux. The corresponding time and horizontally averaged conservation equation for the vertical scalar flux budget is:

$$
\begin{aligned}
\frac{\partial \overline{w^{\prime} C^{\prime}}}{\partial t}=0 & =-\overline{w^{\prime 2}} \frac{\partial \bar{C}}{\partial z}-\frac{\partial \overline{w^{\prime} w^{\prime} C^{\prime}}}{\partial z}-\overline{C^{\prime} \frac{\partial p^{\prime}}{\partial z}} \\
0 & =P_{1}+P_{2}+P_{3}
\end{aligned}
$$

where $p^{\prime}$ is the static pressure perturbations.

In Eq. [6], scalar drag, and waving source production were neglected (Finnigan, 1985). The terms $P_{2}$ and $P_{3}$ are unknowns requiring closure approximations. The flux transport term $\left(P_{2}\right)$ is modeled after Meyers and Paw U (1987), and the dissipation term $\left(P_{3}\right)$ is modeled after Finnigan (1985). These approximations are:

$$
\begin{aligned}
\overline{w^{\prime} w^{\prime} C^{\prime}}= & \frac{\tau}{C_{8}}\left[-\overline{w^{\prime} w^{\prime} w^{\prime}}\left(\frac{\partial \bar{C}}{\partial z}\right)-\overline{w^{\prime} C^{\prime}}\left(\frac{\partial \overline{w^{\prime} w^{\prime}}}{\partial z}\right)\right. \\
& \left.-2 \overline{w^{\prime} w^{\prime}}\left(\frac{\partial w^{\prime} C^{\prime}}{\partial z}\right)\right] \\
\overline{C^{\prime} \frac{\partial p^{\prime}}{\partial z}} & =\overline{w_{4} \frac{w^{\prime} C^{\prime}}{\tau}}
\end{aligned}
$$

where $C_{4}$ and $C_{8}$ are closure constants and $\tau$ is an Eulerian time scale given by $\tau=q^{2} / \varepsilon, q\left(=\sqrt{u_{i}^{\prime} u_{i}^{\prime}}\right)$ is a 
characteristic turbulent velocity, $\varepsilon$ is the mean rate of viscous dissipation, and $u_{i}$ are the velocity components in the $x_{1}$ (or $x$ ), $x_{2}$ (or $y$ ), and $x_{3}$ (or $z$ ) directions, respectively, with $x_{1}$ aligned along the mean wind direction so that $\overline{u_{2}}=0$. The relaxation time $\tau$ is only dependent on the velocity statistics and can be computed from momentum higher-order closure models (Meyers and Paw U, 1986; Katul and Albertson, 1998; 1999; Katul and Chang, 1999) or LES techniques (Shaw and Schumann, 1992; Shen and Leclerc, 1997; Dyer et al., 1997; Albertson and Parlange, 1999).

We note that when $P_{2} \ll P_{1}$, the flux-transport term can be neglected and K-theory is recovered to give:

$$
\overline{w^{\prime} C^{\prime}}=-\left(\frac{\tau \sigma_{w}^{2}}{C_{4}}\right) \frac{\partial \bar{C}}{\partial z},
$$

or

$$
K_{\mathrm{m}}=\left(\frac{\tau \sigma_{w}^{2}}{C_{4}}\right) .
$$

Hence, failure of K-theory is commonly attributed to a large flux transport term (e.g., Deardorff, 1978) within the canopy volume (in Eulerian formulations).

Upon combining these closure approximations with the scalar budget, the scalar turbulent flux within the canopy can be computed from (Katul and Albertson, 1999):

$$
A_{1}(z) \frac{\partial^{2} \overline{w^{\prime} C^{\prime}}}{\partial z^{2}}+A_{2}(z) \frac{\partial \overline{w^{\prime} C^{\prime}}}{\partial z}+A_{3}(z) \overline{w^{\prime} C^{\prime}}=A_{4}(z)
$$

where:

$$
\begin{aligned}
& A_{1}(z)=\frac{2 \tau}{C_{8}} \overline{w^{\prime} w^{\prime}} \\
& A_{2}(z)=\frac{\tau}{C_{8}} \frac{\partial \overline{w^{\prime} w^{\prime}}}{\partial z}+2 \frac{\partial}{\partial z}\left(\frac{\tau}{C_{8}} \overline{w^{\prime} w^{\prime}}\right) \\
& A_{3}(z)=\frac{\partial}{\partial z}\left(\frac{\tau \partial \overline{w^{\prime} w^{\prime}}}{C_{8} \partial z}\right)-C_{4} \frac{1}{\tau} \\
& \mathrm{A}_{4}(z)=\overline{w^{\prime} w^{\prime}} \frac{\partial \bar{C}}{\partial z}-\frac{\partial}{\partial z}\left(\frac{\tau}{C_{8}} \overline{w^{\prime} w^{\prime} w^{\prime}}\right) \frac{\partial \bar{C}}{\partial z}-\left(\frac{\tau}{C_{8}} \overline{w^{\prime} w^{\prime} w^{\prime}}\right) \frac{\partial^{2} \bar{C}}{\partial z^{2}}
\end{aligned}
$$

The measured mean concentration profile affects the flux distribution calculations through $\mathrm{A}_{4}(\mathrm{z})$. The flow statistics $w^{\prime} w^{\prime}, w^{\prime} w^{\prime} w^{\prime}$, and $\tau$ can be estimated from momentum transport second-order closure principles, such as the model proposed by Wilson and Shaw (1977) or Wilson (1988) (see Katul and Albertson, 1998). In contrast to LNF, the EUL model of Katul and Albertson (1999) can incorporate non-Gaussian $w$ statistics (e.g., nonzero $\left.\overline{w^{\prime} w^{\prime} w^{\prime}}\right)$ and advective scalar transport. However, the EUL model calculations of $S_{\mathrm{c}}$ and $F_{\mathrm{c}}$ are sensitive to measurement errors in $\bar{C}$ (at least when compared with LNF) because of the lack of any redundancy in the inversion for $S_{\mathrm{c}}$ from measured $\bar{C}$ (Katul and Albertson, 1999; Siqueira et al., 2000). Hence, it is desirable to construct a model that combines advantages of both EUL and LNF. Such a model, known as a Hybrid Eulerian-Lagrangian (HEL), is discussed next.

\section{Hybrid Eulerian-Lagrangian Method}

The hybrid Eulerian-Lagrangian model was proposed by Siqueira et al. (2000) to include many of the advantages of EUL and LNF in one inversion scheme. The method adopts a second-order closure model, similar to the one described above, to estimate the elements of $D_{i j}$ but computes $S_{\mathrm{c}}$ from the robust regression algorithm of Raupach $(1989 a, b)$ given by Eq. [4].

That is, the second-order ordinary differential equation (ODE) describing the concentration profile from a prescribed source is given by:

$$
B_{1}(z) \frac{\partial^{2} \bar{C}}{\partial z^{2}}+B_{2}(z) \frac{\partial \bar{C}}{\partial z}=B_{3}(z)
$$

where:

$$
\begin{aligned}
& B_{1}(z)=\frac{\tau}{C_{8}} \overline{w^{\prime} w^{\prime} w^{\prime}} \\
& B_{2}(z)=-\overline{w^{\prime} w^{\prime}}+\frac{\partial}{\partial z}\left(\frac{\tau}{C_{8}} \overline{w^{\prime} w^{\prime} w^{\prime}}\right) \\
& B_{3}(z)=-\frac{\partial}{\partial z}\left[\frac{\tau}{C_{8}}\left(\overline{w^{\prime} C^{\prime}} \frac{\partial \overline{w^{\prime} w^{\prime}}}{\partial z}+2 \overline{w^{\prime} w^{\prime}} \frac{\partial \overline{\mathrm{w}^{\prime} C^{\prime}}}{\partial z}\right)\right]+C_{4} \frac{\overline{w^{\prime} C^{\prime}}}{\tau}
\end{aligned}
$$

The flux $\overline{w^{\prime} C^{\prime}}$ is calculated by simply integrating the unit source placed at one layer via Eq. [5] to determine the corresponding $\bar{C}$ from this unit source. In essence, the elements of $D_{i j}$ are computed by (i) positioning a unit source at a layer located at node $j$; (ii) integrating this source profile to obtain the $\overline{w^{\prime} C^{\prime}}$ profile; (iii) solving the ODE in Eq. [7] for the concentration at all $i$ nodes resulting from the unit source placed at node $j$, where $n$ is the number of layers within and above the canopy for which concentration measurements are available; and (iv) repeating this procedure for $j=1, . . m$ ( $m<$ $n$ ) to obtain all the elements of the $D_{i j}$ matrix, where $m$ is the numbers of source layers.

The scheme includes the LNF regression inversion in a more physically sound forward calculation of $D_{i j}$, which also includes the effects of non-zero $\overline{w^{\prime} w^{\prime} w^{\prime}}$ on $D_{i j}$ through the coefficients $B_{1}$ and $B_{2}$.

\section{Local Buoyancy Effects on Inversion Schemes: A Case Study with Sensible Heat}

Thus far, all three methods assumed neutral atmospheric conditions. To account for local buoyancy effects, we consider the EUL method of Katul and Albertson (1999) as a case study. The time and horizontally averaged conservation equation for $\left\langle\overline{w^{\prime} T^{\prime}}\right\rangle$ as a function of $\langle\bar{T}\rangle$ for stratified turbulent flows is

$$
\begin{aligned}
\frac{\partial\left\langle\overline{w^{\prime} T^{\prime}}\right\rangle}{\partial t} & =0 \\
& =-\left\langle\overline{w^{\prime 2}}\right\rangle \frac{\partial\langle\bar{T}\rangle}{\partial z}-\frac{\partial\left\langle\overline{w^{\prime} w^{\prime} T^{\prime}}\right\rangle}{\partial z} \frac{1}{\rho}\left\langle\overline{T^{\prime} \frac{\partial p^{\prime}}{\partial z}}\right\rangle+\frac{g}{\bar{T}}\left\langle\overline{T_{v}^{\prime 2}}\right\rangle
\end{aligned}
$$

When compared with Eq. [6], the new term in Eq. [8] is the buoyancy production term, which varies with the virtual temperature variance. To estimate $\left\langle\overline{T^{\prime 2}}\right\rangle$, a temperature variance budget, given by 
$\frac{\partial\left\langle\overline{T^{\prime 2}}\right\rangle}{\partial t}=0=-2\left\langle\overline{w^{\prime} T^{\prime}}\right\rangle \frac{\partial \bar{T}}{\partial \mathrm{z}}-\frac{\partial\left\langle\overline{w^{\prime} T^{\prime} T^{\prime}}\right\rangle}{\partial z}-2\left\langle\varepsilon_{T T}\right\rangle$

is used with the following closure models for the transport term $\left\langle\overline{\left.w^{\prime} T^{\prime} T^{\prime}\right\rangle}\right.$ and the dissipation term $\left\langle\varepsilon_{T T}\right\rangle$ :

$$
\begin{aligned}
\left\langle\overline{w^{\prime} T^{\prime} T^{\prime}}\right\rangle & =\frac{\tau}{C_{8}}\left(-2\left\langle\overline{w^{\prime} w^{\prime} T^{\prime}}\right\rangle-\overline{w^{\prime 2}} \frac{\partial\left\langle\overline{T^{\prime 2}}\right\rangle}{\partial z}-2\left\langle\overline{w^{\prime} T^{\prime}}\right\rangle \frac{\partial\left\langle\overline{w^{\prime} T^{\prime}}\right\rangle}{\partial z}\right) \\
\left\langle\varepsilon_{T T}\right\rangle & =C_{5} \frac{\overline{T^{\prime 2}}}{\tau}
\end{aligned}
$$

where $C_{5}$ is a closure constant.

Upon combining these approximations, a set of second-order ODEs can be derived for estimating $\left.\overline{\left\langle w^{\prime} T^{\prime}\right.}\right\rangle$ and $\left\langle\overline{T^{\prime 2}}\right\rangle$. The boundary conditions proposed by Katul and Albertson (1999) and Meyers and Paw U (1987) were adopted. This approach was first proposed by Siqueira and Katul (2002), and they determined the closure constants to be $C_{4}=2.5, C_{8}=3.0$ and $C_{5}=0.5$, also used here.

\section{EXPERIMENTS}

Two sets of experiments were conducted at the Blackwood Division of the Duke Forest near Durham, NC $\left(36^{\circ} 02^{\prime} \mathrm{N}, 79^{\circ} 8^{\prime} \mathrm{W}\right.$, elevation $\left.=163 \mathrm{~m}\right)$. The first set is a heat dispersion experiment aimed at assessing how well the models recover the vertical flux distribution. The second set is a long-term heat, $\mathrm{CO}_{2}$ and $\mathrm{H}_{2} \mathrm{O}$ dispersion experiments aimed at assessing how well the models recover the temporal variability of land surface fluxes above the canopy. Details of the setup are presented in Siqueira et al. (2000). However, for completeness, a brief review is provided. The stand is a uniformly planted loblolly pine (Pinus taeda L.) forest that extends 300 to $600 \mathrm{~m}$ in the east-west direction and $1000 \mathrm{~m}$ in the north-south direction. The mean canopy height was $14.0 \mathrm{~m}( \pm 0.5 \mathrm{~m})$ in 1998 . Topographic variations within the stand are small (terrain slope changes $<5 \%$ ) such that the influence of topography on the turbulent fluxes can be neglected (Kaimal and Finnigan, 1994).

\section{The Heat Dispersion Experiment}

To assess the vertical distribution of scalar fluxes inside the canopy, simultaneous mean temperature profiles and turbulence statistics were measured inside the canopy. The mean temperature was measured at eight levels $(1.5,3.5,5.5,7.5,9.5,11.5,13.5$, and $15.5 \mathrm{~m})$ using shielded Copper Constantan thermocouples (20 gauge, diameter $=0.812 \mathrm{~mm}$ ). The thermocouples were sampled every $1 \mathrm{~s}$ and averaged every $1800 \mathrm{~s}$ (30 min). Calibration of the thermocouples is described in Siqueira et al. (2000). These thermocouple measurements are also used for the long-term flux monitoring.

The velocity statistics and turbulent heat flux distribution were simultaneously measured at 3.0, 4.9, 8.6, 10.9, 12.2, and $15.5 \mathrm{~m}$ above the forest floor using six Campbell Scientific triaxial sonic anemometers (CSAT3, Campbell Scientific, Logan, UT). The sampling frequency was $10 \mathrm{~Hz}$, and the sampling period was $1800 \mathrm{~s}$ (30 min) per run. More than 150 runs were collected in
2000 during two periods, 19 to 23 April and 20 to 27 Oct., and for a wide range of atmospheric stability conditions.

\section{The Long-Term Mass and Heat Dispersion Experiments}

To assess how well these three methods reproduce the temporal patterns of scalar fluxes above the canopy, a long-term record of $\mathrm{CO}_{2}$, water vapor, and sensible heat fluxes above the canopy and mean $\mathrm{CO}_{2}$-water vapor concentration, and mean temperature profiles within the canopy were used. This data set is being collected as part of an ongoing long-term $\mathrm{H}_{2} \mathrm{O}-\mathrm{CO}_{2}$ flux monitoring initiative at the Duke AmeriFlux site (Katul et al., 1999; Lai et al., 2000a,b). We focus on a longterm temperature, water vapor, and $\mathrm{CO}_{2}$ data set collected from March 2000 to September 2001, which resulted in 1616530-min simultaneous flux and concentration profile runs for all three scalars.

The sensible heat, $\mathrm{CO}_{2}$, and $\mathrm{H}_{2} \mathrm{O}$ fluxes above the canopy were measured by an eddy-covariance system comprised of a Licor- $6262 \mathrm{CO}_{2} / \mathrm{H}_{2} \mathrm{O}$ infrared gas analyzer (LI-COR, Lincoln, NE) and a Campbell Scientific triaxial sonic anemometer. The CSAT3 was positioned at $15.5 \mathrm{~m}$ above the ground surface and was anchored on a horizontal bar extending $1.5 \mathrm{~m}$ away from the walkup tower top. The infrared gas analyzer was housed in an enclosure $4.5 \mathrm{~m}$ from the inlet cup, which was positioned just under the CSAT3. Sampling flow rates, tube attenuation, and lag time corrections are discussed in Katul et al. (1997a,b).

The eddy-covariance instruments were sampled at $5 \mathrm{~Hz}$ using a Campbell Scientific 21X data logger and processed using the procedures described in Katul et al. $(1997 a, b)$ with scalar covariance computed after maximizing the cross correlation between vertical velocity fluctuations and scalar concentration fluctuations for each 30-min run. Other measurement and processing corrections were described in Katul et al. (1997a,b).

In addition to the thermocouples, a multi-port system was installed to measure the mean $\mathrm{H}_{2} \mathrm{O}$ and $\mathrm{CO}_{2}$ concentration inside the canopy at seven levels above the ground surface $(3.5,5.5,7.5,9.5,11.5,13.5$, and $15.5 \mathrm{~m})$. The concentration at each level was sampled for $60 \mathrm{~s}$ (45-s sampling and 15-s purging) at the beginning, the middle, and the end of a 30-min sampling duration by another Licor 6262 housed in a wooden shed 15 m away from the tower. The flow rate within the tube (i.d. = $4.23 \mathrm{~mm}$ ) was set at $1.5 \times 10^{-5} \mathrm{~m}^{3} \mathrm{~s}^{-1}$ to dampen all turbulent fluctuations.

The shoot silhouette area index was measured in the vertical at increments of $1 \mathrm{~m}$ by a pair of Licor LAI 2000 plant canopy analyzers four times a year starting in 1996. A subset of this data set was used to generate the flow statistics needed by all three methods. In a first-order analysis, to model the flow field, it was assumed that the LAI 2000 plant canopy analyzer measurement is analogous to the leaf area density $a(z)$. Hence, with such an approximation, the Wilson and Shaw (1977) closure model described in Appendix A can be used to compute the flow statistics. 

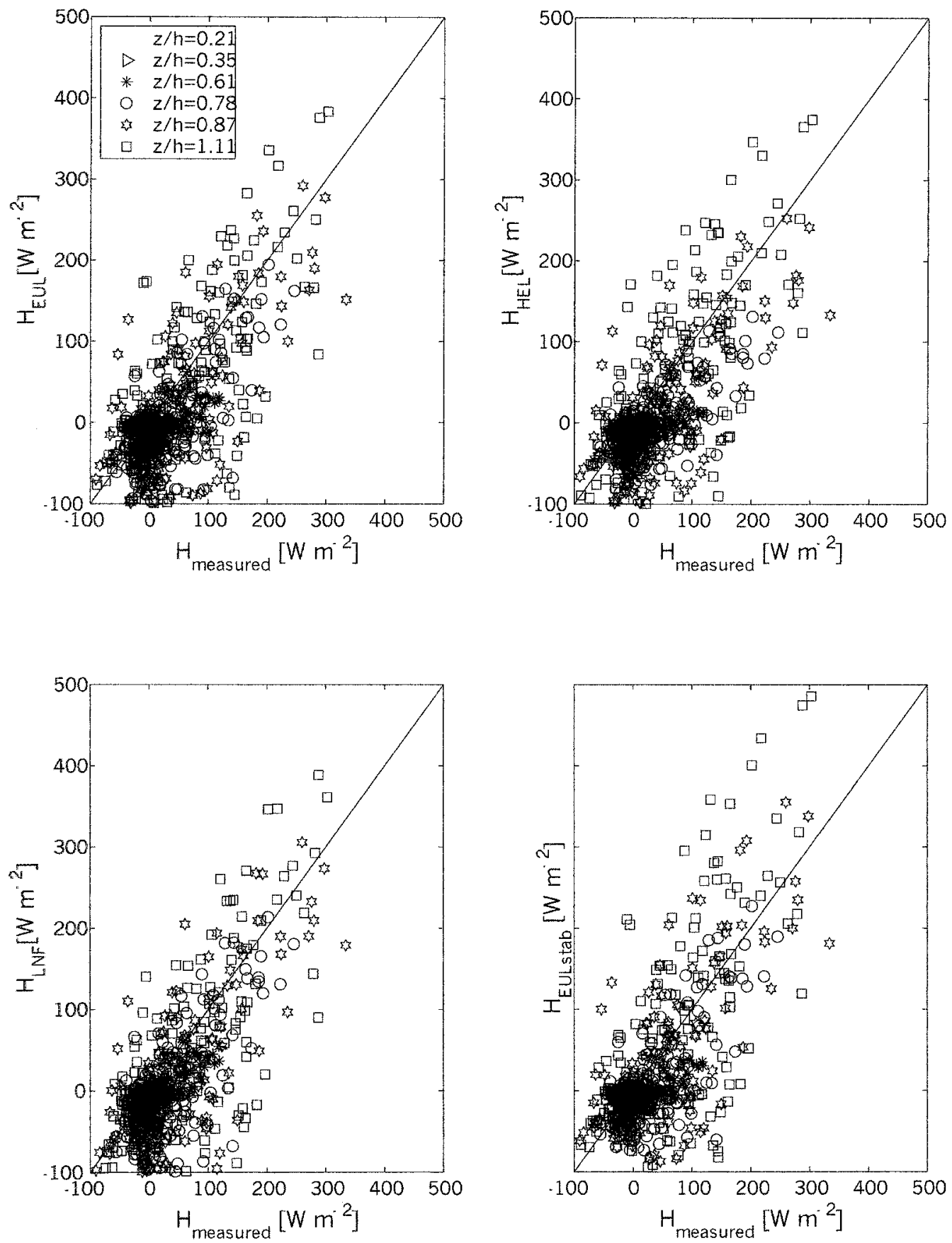

Fig. 2. Comparison between 30-min measured and modeled sensible heat flux $(\mathrm{H})$ at all six levels within the canopy. Modeled sensible heat fluxes by the Eulerian method, corrected for local atmospheric stability, are also shown. Table 1 lists the regression statistics for these comparisons.

\section{RESULTS}

We present the comparisons between fluxes predicted by the three inverse models and measured by eddycovariance methods in time and depth within the canopy volume.

\section{Vertical Variation: Heat Dispersion Experiment}

Using the three inverse models, we modeled the sensible heat flux within the canopy at six levels and compared the model calculations with eddy covariance mea- surements (Fig. 2) for each 30-min run. All three models reproduced the statistics of the 30-min sensible heat fluxes reasonably well (Table 1) across all levels. The RMSE from all three models (not corrected for local atmospheric stability) was about $50 \mathrm{~W} \mathrm{~m}^{-2}$. Examination of Table 1 also suggests that stability corrections to the EUL model significantly improved the overall comparison between measured and modeled sensible heat flux. We consider next whether such an agreement persists over a broad range of time scales and for different scalars such as water vapor and $\mathrm{CO}_{2}$. 

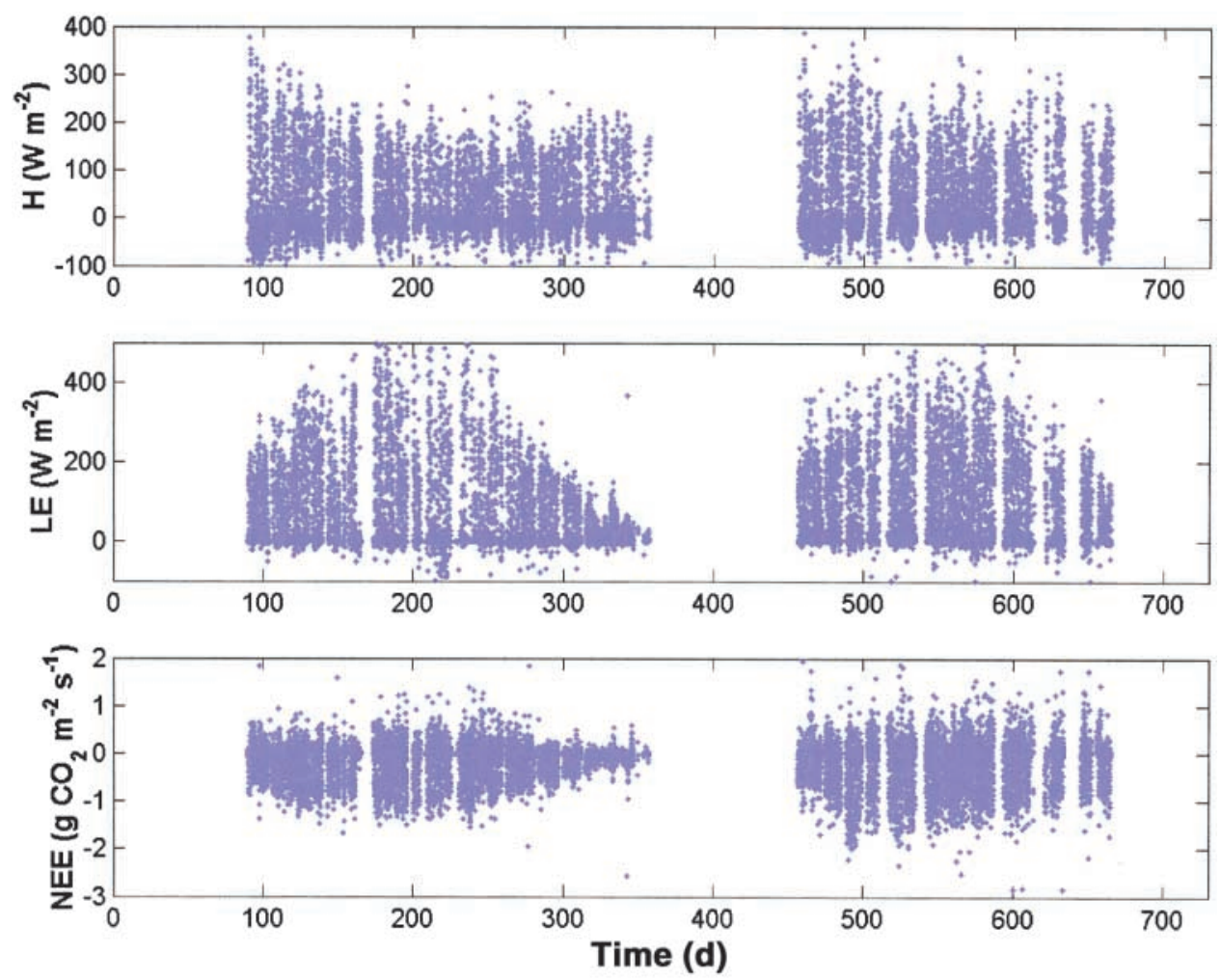

Fig. 3. Time series of eddy-covariance measured sensible heat flux (H) (top), latent heat flux (LE) (middle), and $\mathrm{CO}_{2}$ flux (or Net Ecosystem Exchange, NEE) (bottom) are shown. Note the large and random gaps in the record. Abscissa origin refers to 1 Jan. 2000.

\section{Temporal Variations and Multiscale Attributes of Land-Surface Fluxes}

We compare spectrally the modeled and measured sensible heat, latent heat, and $\mathrm{CO}_{2}$ fluxes. A spectral comparison between measured and modeled fluxes is more illustrative than standard regression analysis (e.g., Table 1) given the inherent multi-scale attributes of these three land-surface fluxes. For example, flux variability at time scales ranging from hours to a week is primarily controlled by environmental variables such as incident solar radiation, air temperature, vapor pressure deficit, and precipitation. At seasonal time scales, variability in canopy attributes such as leaf area density, and leaf physiological attributes such as maximum quantum efficiency, leaf absorptivity, photosynthetically active radiation, or maximum Rubisco capacity all introduce

Table 1. Comparison between measured and modeled sensible heat $\left(\mathrm{W} \mathrm{m}^{-2}\right)$ for all six levels and atmospheric stability conditions. The regression model is $\boldsymbol{H}(\operatorname{model})=$ Slope $\boldsymbol{H}(\mathrm{ec})+$ Intercept. The correlation coefficient $(R)$ and the root-meansquared error (RMSE, [W $\left.\mathrm{m}^{-2}\right]$ ) are shown along with the total number of points used $(\mathrm{N}) . \dagger$

\begin{tabular}{lcrrc}
\hline Sensible heat & EUL & HEL & LNF & EUL stab \\
\hline$N$ & 1314 & \multicolumn{1}{c}{1314} & \multicolumn{1}{c}{$\mathbf{1 3 1 4}$} & \multicolumn{1}{c}{1314} \\
Slope & $\mathbf{0 . 7 1}$ & $\mathbf{0 . 6 9}$ & $\mathbf{0 . 7 5}$ & $\mathbf{0 . 8 2}$ \\
Intercept, W m m$^{-2}$ & $-\mathbf{1 3 . 8 8}$ & $-\mathbf{1 4 . 9 2}$ & $-\mathbf{1 8 . 2 3}$ & -4.93 \\
RMSE, W m ${ }^{-2}$ & $\mathbf{5 2 . 9 3}$ & $\mathbf{5 3 . 5 3}$ & $\mathbf{5 9 . 9 3}$ & $\mathbf{4 6 . 4 7}$ \\
$\boldsymbol{R}$ & $\mathbf{0 . 6 4}$ & $\mathbf{0 . 6 3}$ & $\mathbf{0 . 6 0}$ & $\mathbf{0 . 7 1}$ \\
\hline
\end{tabular}

$\dagger$ EUL, Eulerian closure "inverse" model; LNF, localized near field theory. additional "variances". Hence, to diagnose how well the inverse models reproduce the flux variability at such a broad spectrum of time scales a spectral representation is most suitable. We note that standard Fourier spectral analysis cannot be readily used for such spectral comparisons. This is, in part, due to the unavoidable random (and large) gaps in both measured and modeled flux time series (see, e.g., Fig. 3). Towards this end, orthonormal wavelet transformation with a localized basis function in time (e.g., Haar wavelet) is used. The computation of orthonormal wavelet spectra from the wavelet transform of such "gap-infected" time series is described elsewhere (Katul et al., 2001a).

In Fig. 4, predicted and measured Haar wavelet spectra of sensible heat, latent heat, and $\mathrm{CO}_{2}$ fluxes are compared. The figure demonstrates that:

1. Neither measured nor modeled flux spectra decay as the time scale increases (even after $1 \mathrm{yr}$ ). Clearly, with increasing time scales beyond a single year, a new source of variability associated with growth and stand age becomes dominant. This implies that the flux time series is a nonstationary process and hence cannot be properly analyzed by standard Fourier methods.

2. The EUL corrected for atmospheric stability greatly improved the agreement between predicted and measured sensible heat flux spectra, at least when compared with the original EUL model of Katul and Albertson (1999). This is in concert with the findings in Fig. 2 and Table 1. 
3. The LNF overpredicted variability at all time scales for $\mathrm{CO}_{2}$ and water vapor fluxes when compared with EUL and HEL. Interestingly, Leuning (2000), Leuning et al. (2000), Siqueira et al. (2000), and Katul et al. (2001b) reported similar overestimation in the time domain. Also, EUL and HEL systematically underestimated the measured flux variability at time scales ranging from 1 to $10 \mathrm{~d}$, and for all three scalars. These time scales are associated with day-to-day differences in environmental factors forced by different weather patterns.

4. Measured flux spectra appear to be bounded by all three inverse models and for all the three scalars analyzed.

\section{DISCUSSION AND CONCLUSION}

This study described recent developments in inverse methods to infer distributions and strengths of scalar sources and sinks of water vapor, $\mathrm{C}$, and heat within the canopy volume for a wide range of time scales from $30 \mathrm{~min}$ to years. The inverse approaches considered do not resort to empirical relationship between turbulent scalar fluxes and mean concentration gradients.

Given that these inverse models do not require any hydrologic, climatic, or ecophysiological input, and given that the measured flux variability spans three decades, the comparison between measured and modeled fluxes is a promising first step, but still leaves much to be desired. It is clear from Fig. 4 that correcting for atmospheric stability is a first step towards improving the frequency response of the Eulerian models. Future inverse schemes clearly benefit from explicitly considering the role of local atmospheric stability and should resort to a nonsteady formulation in their continuity and flux-budget models.

Also, given that the inverse problem itself is ill posed, we envision the application of all the three methods for routine source inference to be more beneficial than recommending a particular method. These methods differ in their basic assumptions; hence, agreement amongst all three methods adds confidence in the modeled source strength and simplifications for a particular scalar concentration profile. Similarly, disagreement between them highlights the magnitude (and location) of the uncertainty in the modeled source distribution (in space) or the failure to capture flux variability at a particular time scale.

\section{ACKNOWLEDGMENTS}

Support for this study was provided by the National Science Foundation (NSF-EAR-99-03471), the Biological and Environmental Research (BER) Program, U.S. Department of Energy, through the Southeast Regional Center (SERC) of the National Institute for Global Environmental Change (NIGEC), and through the Terrestrial Carbon Processes Program (TCP). The second author is supported by the "Conselho Nacional de Desenvolvimento Científico e Tecnológico (CNPq)" of Brazil.

\section{APPENDIX}

\section{Wilson and Shaw's Model}

Upon time and horizontally averaging the mean momentum and Reynolds stress equations for neutral conditions, the second-order closure model of Wilson and Shaw (1977) reduces to

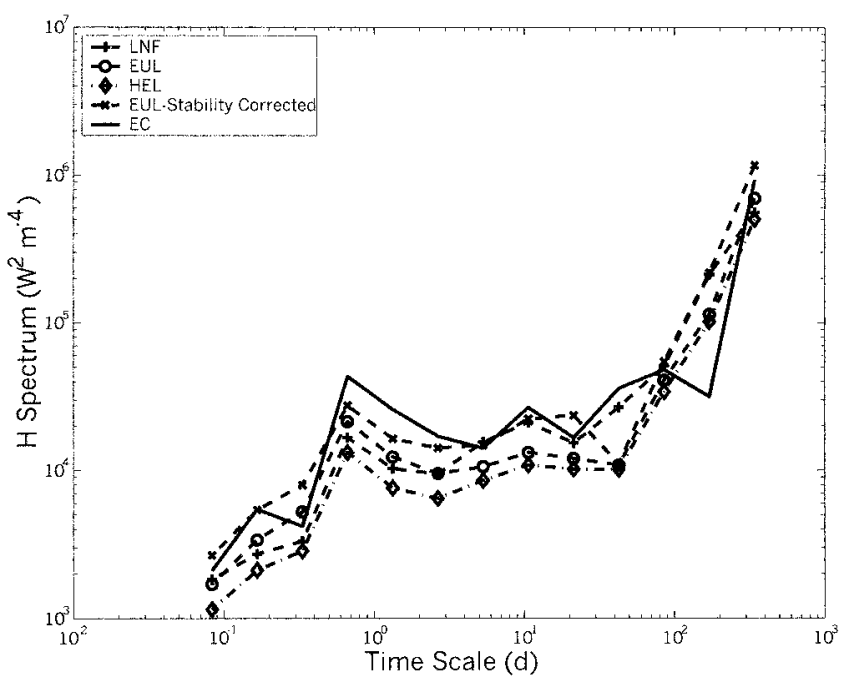

Fig. 4a. Comparison between measured and modeled Haar wavelet spectra for sensible heat flux $(\mathrm{H})$.

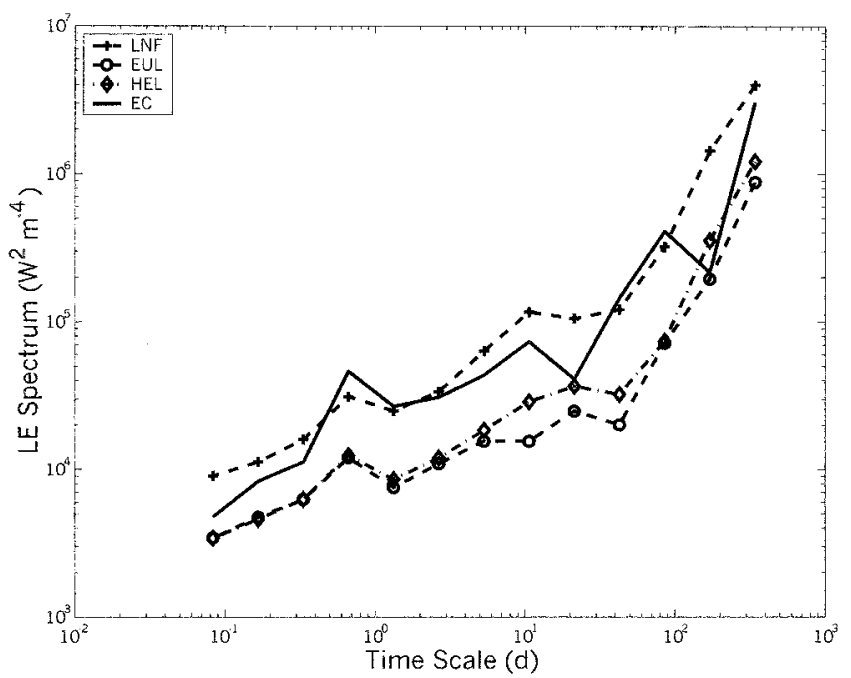

Fig. 4b. Comparison between measured and modeled Haar wavelet spectra for latent heat flux (LE).

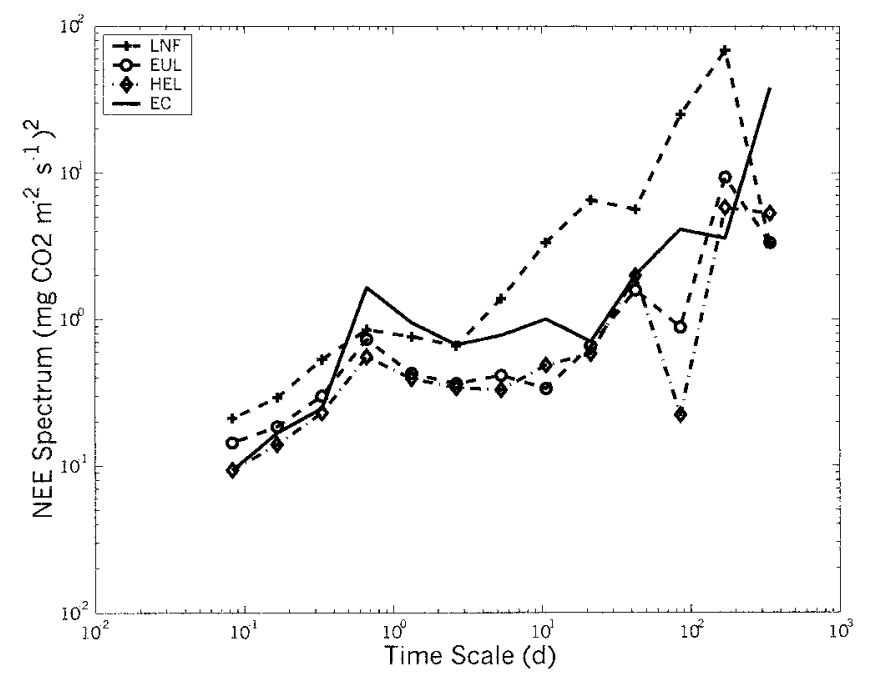

Fig. 4c. Comparison between measured and modeled Haar wavelet spectra for $\mathrm{CO}_{2}$ fluxes (or net ecosystem exchange, NEE). 


$$
\begin{aligned}
0= & -\frac{\mathrm{d}\left\langle\overline{u^{\prime} w^{\prime}}\right\rangle}{\mathrm{d} z}-C_{\mathrm{d}} a(z)\langle\bar{u}\rangle^{2} \\
0= & -\left\langle\overline{w^{\prime 2}}\right\rangle \frac{\mathrm{d}\langle\bar{u}\rangle}{\mathrm{d} z}+2 \frac{\mathrm{d}}{\mathrm{d} z}\left(q \lambda_{1} \frac{\mathrm{d}\left\langle\overline{\left.u^{\prime} w^{\prime}\right\rangle}\right.}{\mathrm{d} z}\right)-\frac{q\left\langle\overline{u^{\prime} w^{\prime}}\right\rangle}{3 \lambda_{2}}+C_{w} q^{2} \frac{\mathrm{d}\langle\bar{u}\rangle}{d z} \\
0= & -2\left\langle\overline{u^{\prime} w^{\prime}}\right\rangle \frac{\mathrm{d}\langle\bar{u}\rangle}{\mathrm{d} z}+\frac{\mathrm{d}}{\mathrm{d} z}\left(q \lambda_{1} \frac{\mathrm{d}\left\langle\overline{u^{\prime 2}}\right\rangle}{\mathrm{d} z}\right)+2 C_{\mathrm{d}} a(z)\langle\bar{u}\rangle^{3} \\
0 & \left.-\frac{q}{3 \lambda_{2}}\left(\overline{\left\langle\overline{u^{\prime 2}}\right\rangle}-\frac{q^{2}}{3}\right)-\frac{2 q^{3}}{3 \lambda_{3}}\left(q \lambda_{1} \frac{\mathrm{d}\left\langle\overline{v^{\prime 2}}\right\rangle}{\mathrm{d} z}\right)-\frac{q}{3 \lambda_{2}}\left(\overline{\left\langle v^{\prime 2}\right.}\right\rangle-\frac{q^{2}}{3}\right)-\frac{2}{3} \frac{q^{3}}{\lambda_{3}} \\
0= & \frac{\mathrm{d}}{\mathrm{d} z}\left(3 q \lambda_{1} \frac{\mathrm{d}\left\langle\overline{w^{\prime 2}}\right\rangle}{\mathrm{d} z}\right)-\frac{q}{3 \lambda_{2}}\left(\overline{\left\langle w^{\prime 2}\right\rangle}-\frac{q^{2}}{3}\right)-\frac{2}{3} \frac{q^{3}}{\lambda_{3}}
\end{aligned}
$$

In Eq. [A.1], $u_{\mathrm{i}}\left(u_{1}=u, u_{2}=v, u_{3}=w\right)$ are the instantaneous velocity components along $x_{\mathrm{i}} ; x_{\mathrm{i}}\left(x_{1}=x, x_{2}=y, x_{3}=z\right)$ are the longitudinal, lateral, and vertical directions, respectively; $\lambda_{1}, \lambda_{2}$, and $\lambda_{3}$ are characteristic length scales for the triplevelocity correlation, the pressure-velocity gradient correlation, and viscous dissipation, respectively; $C_{\mathrm{w}}$ is a constant; $C_{\mathrm{d}}$ is the foliage drag coefficient; and $a(z)$ is the leaf area density.

With estimates of the characteristic length scales $\lambda_{1}, \lambda_{2}$, and $\lambda_{3}$, and the constant $C_{\mathrm{w}}$ the five ordinary differential equations in [A.1] can be solved for the five flow variables $\langle\bar{u}\rangle$, $\left.\left\langle\overline{u^{\prime} w^{\prime}}\right\rangle,\left\langle\overline{u^{\prime 2}}\right\rangle, \overline{\left\langle v^{\prime 2}\right.}\right\rangle$, and $\left.\overline{\left\langle w^{\prime 2}\right.}\right\rangle$ if appropriate boundary conditions are specified. The following neutral boundary conditions were used here:

$$
\text { at } z / h=1.1\left[\begin{array}{l}
\frac{\langle\bar{u}\rangle}{u *}=5.5 \\
\frac{\sigma_{u}}{u *}=2.4 \\
\frac{\sigma_{v}}{u *}=1.95 \\
\frac{\sigma_{w}}{u *}=1.1 \\
\frac{\langle u w\rangle}{u *^{2}}=-1.0 \\
\text { at } z / h=1.1\left[\begin{array}{l}
\frac{\langle\bar{u}\rangle}{u *}=0 \\
\frac{\sigma_{v}}{u *}=0 \\
\frac{\sigma_{v}}{u *}=0 \\
\frac{\sigma_{w}}{u *}=0 \\
\frac{\left\langle u *^{2}\right.}{u w}=0
\end{array}\right.
\end{array}\right.
$$

While more complex second-order closure schemes (e.g., Wilson, 1988; Ayotte et al., 1999) and third-order closure schemes have been developed for vegetation flow, recent studies by Katul and Albertson (1998) and Katul and Chang (1999) suggest that the Wilson and Shaw (1977) model performance is comparable to Wilson's (1988) and another third-order closure model for this pine forest.

\section{REFERENCES}

Albertson, J.D., and M.B. Parlange. 1999. Surface length scales and shear stress: Implications for land-atmosphere interaction over complex terrain. Water Resour. Res. 35:2121-2132.

Ayotte, K.W., J.J. Finnigan, and M.R. Raupach. 1999. A second-order closure for neutrally stratified vegetative canopy flows. BoundaryLayer Meteorol. 90:189-216.

Baldocchi, D.D., E. Falge, L. Gu, R. Olson, D. Hollinger, S. Running, P. Anthoni, Ch. Bernhofer, K. Davis, J. Fuentes, A. Goldstein, G. Katul, B. Law, X. Lee, Y. Malhi, T. Meyers, J.W. Munger, W. Oechel, K. Pilegaard, H.P. Schmid, R. Valentini, S. Verma, T. Vesala, K. Wilson, and S. Wofsy. 2001. FLUXNET: A new tool to study the temporal and spatial variability of ecosystem-scale carbon dioxide, water vapor and energy flux densities. Bull. Am. Meteorol. Soc. 82:2415-2435.

Brutsaert, W. 1982. Evaporation into the atmosphere: Theory, history, and applications. Kluwer Academic Publishers, Dordrecht, The Netherlands.

Chen, F., R.A. Pielke Sr., and K. Mitchell. 2001. Development and application of land-surface models for mesoscale atmospheric models: Problems and promises. p. 107-135. In V. Lakshmi et al. (ed.) Land surface hydrology, meterology, and climate: Observations and modeling. Water Science and Application, Vol. 3. American Geophysical Union, Washington, DC.

Coppin, P.A., M.R. Raupach, and B.J. Legg. 1986. Experiments on scalar dispersion within a model canopy. Part II: An elevated plane source. Boundary-Layer Meteorol. 35:167-191.

Deanmead, O.T. 1995. Novel meteorological methods for measuring trace gas fluxes. Philos. Trans. R. Soc. London Ser. A 351:383-396.

Deanmead, O.T., and E.F. Bradley. 1985. Flux gradient relationships in a forest canopy. p. 421-442. In B.A. Hutchison and B.B. Hicks (ed.) The forest-atmosphere interaction. D. Reidel Publishing, Dordrecht, The Netherlands.

Deanmead, O.T., and M.R. Raupach. 1993. Methods for measuring atmospheric gas transport in agricultural and forest system. p. 1943. In J.M. Duxbury et al. (ed.) Agricultural ecosystem effects on trace gases and global climate change. ASA Spec. Publ. 55. ASA, CSSA, and SSSA, Madison, WI.

Deardorff, J.W. 1978. Closure of second and third moment rate equations for diffusion in homogeneous turbulence. Phys. Fluids 21: $525-530$.

Dyer, M.J., E.G. Patton, and R.H. Shaw. 1997. Turbulent kinetic energy budgets from a large eddy simulation of air flow above and within a forest canopy. Boundary-Layer Meteorol. 84:23-43.

Finnigan, J.J. 1985. Turbulent transport in plant canopies. p. 443-480. In B.A. Hutchinson and B.B. Hicks (ed.) The forest-atmosphere interactions. D. Reidel, Norwell, MA.

Finnigan, J.J. 2000. Turbulence in plant canopies. Annu. Rev. Fluid Mechanics 32:519-571.

Finnigan, J.J., and M.R. Raupach. 1987. Transfer processes within plant canopies in relation to stomatal characteristics. p. 385-429. In E.M. Zeiger et al. Stomatal function. Stanford University Press, Stanford, CA.

Hornberger, G. 2001. Global water cycle science plan, a report to the USGCRP from the Water Cycle Study Group. U.S. Global Change Research Program, Washington, DC.

Jury, W.A., W.R. Gardner, and W.H. Gardner. 1991. Soil physics. John Wiley, New York, NY.

Kaiser, J. 1997. Climate change-A new network aims to take the world's $\mathrm{CO}_{2}$ pulse source. Science 281:506-507.

Kaimal, J.C., and J.J. Finnigan. 1994. Atmospheric boundary layer flows: Their structure and measurement. Oxford Univ. Press, New York, NY.

Katul, G.G., and J.D. Albertson. 1998. An investigation of higherorder closure models for a forested canopy. Boundary-Layer Meteorol. 89:47-74.

Katul, G.G., and J.D. Albertson. 1999. Modeling $\mathrm{CO}_{2}$ sources, sinks and fluxes within a forest canopy. J. Geophys. Res. 104:6081-6091.

Katul, G.G., and W.H. Chang. 1999. Principal length scales in secondorder closure models for canopy turbulence. J. Appl. Meteorol. 38:1631-1643.

Katul, G.G., C.I. Hsieh, D. Bowling, K. Clark, N. Shurpali, A. Turnipseed, J. Albertson, K. Tu, D. Hollinger, B. Evans, B. Offerle, D. Anderson, D. Ellsworth, C. Vogel, and R. Oren. 1999. Spatial 
variability of turbulent fluxes in the roughness sublayer of an evenaged pine forest. Boundary-Layer Meteorol. 93:1-28.

Katul, G.G., C.I. Hsieh, G. Kuhn, D. Ellsworth, and D. Nie. 1997a. Turbulent eddy motion at the forest-atmosphere interface. J. Geophys. Res. 102:13409-13421.

Katul, G.G., C.T. Lai, K. Schafer, B. Vidakovic, J.D. Albertson, D. Ellsworth, and R. Oren. 2001a. Multiscale analysis of vegetation surface fluxes: From seconds to years. Adv. Water Resour. 24:1119-1132.

Katul, G.G., R. Leuning, J. Kim, O.T. Denmead, A. Miyata, and Y. Harazono. 2001b. Estimating $\mathrm{CO}_{2}$ source/sink distributions within a rice canopy using higher-order closure model. Boundary-Layer Meteorology 98:103-125.

Katul, G.G., R. Oren, D. Ellsworth, C.I. Hsieh, N. Phillips, and K. Lewin. 1997b. A Lagrangian dispersion model for predicting $\mathrm{CO}_{2}$ sources, sinks, and fluxes in a uniform loblolly pine (Pinus taeda L.) stand. J. Geophys. Res. 102:9309-9321.

Lai, C.T., G.G. Katul, D. Ellsworth, and R. Oren. 2000a. Modelling vegetation-atmosphere $\mathrm{CO}_{2}$ exchange by a coupled Eulerian-Lagrangian approach. Boundary-Layer Meteorol. 95:91-122.

Lai, C.T., G.G. Katul, R. Oren, D. Ellsworth, and K. Schäfer. 2000b. Modeling $\mathrm{CO}_{2}$ and water vapor turbulent flux distributions within a forest canopy. J. Geophys. Res. 105:26333-26351.

Leuning, R. 2000. Estimation of scalar source/sink distributions in plant canopies using Lagrangian dispersion analysis: Corrections for atmospheric stability and comparison with a multilayer canopy model. Boundary-Layer Meteorol. 96:293-314.

Leuning, R., O.T. Denmead, A. Miyata, and J. Kim. 2000. Source/sink distributions of heat, water vapour, carbon dioxide and methane in a rice canopy estimated using Lagrangian dispersion analysis. Agric. For. Meteorol. 104:233-249.

Massman, W.J., and J.C. Weil. 1999. An analytical one dimensional second-order closure model of turbulence statistics and the Lagrangian time scale within and above plant canopies of arbitrary structure. Boundary-Layer Meteorol. 91:81-107.

Maurer, E.P., G. Donnell, D. Lettenmaier, and J. Roads. 2001. Evaluation of NCEP/NCAR reanalysis water and energy budgets using macroscale hydrologic model simulations. p. 137-158. In V. Lakshmi et al. (ed.) Land surface hydrology, meterology, and climate: Observations and modeling. Water Science and Application, Vol. 3. American Geophysical Union, Washington, DC.

McNaughton, K.G., and B.J.J.M. Van den Hurk. 1995. A lagrangian revision of the resistors in the two- layer model for calculating the energy budget of a plant canopy. Boundary-Layer Meteorol. 74: 261-288.

Meyers, T., and K.T. Paw U. 1986. Testing of a higher-order closure model for modeling airflow within and above plant canopies Boundary-Layer Meteorol. 37:297-311.

Meyers, T., and K.T. Paw U. 1987. Modeling the plant canopy micrometeorology with higher-order closure principles. Agric. For. Meteorol. 41:143-163.

Raupach, M.R. 1988. Canopy transport processes p. 95-127. In W.L.
Steffen (ed.) Flow and transport in the natural environment Springer-Verlag, New York, NY.

Raupach, M.R. 1989a. Applying Lagrangian fluid mechanics to infer scalar source distributions from concentration profiles in plant canopies. Agric. For. Meteorol. 47:85-108

Raupach, M.R. 1989b. A practical Lagrangian method for relating scalar concentrations to source distributions in vegetation canopies. Q.J.R. Meteorol. Soc. 115:609-632.

Raupach, M.R., O.T. Denmead, and F.X. Dunin. 1992. Challenges in linking atmospheric $\mathrm{CO}_{2}$ concentrations to fluxes at local and regional scales. Aust. J. Bot. 40:697-716.

Raupach, M.R., J.J. Finnigan, and Y. Brunet. 1996. Coherent eddies and turbulence in vegetation canopies: The mixing-layer analogy. Boundary-Layer Meteorol. 78:351-382.

Raupach, M.R., and R.H. Shaw. Averaging procedures for flow within vegetation canopies. Boundary-Layer Meteorol. 22:79-90.

Raupach, M.R., and A.S. Thom. 1981. Turbulence in and above canopies. Annu. Rev. Fluid Mech. 13:97-129.

Sarmiento, J., and S.C. Wofsy. 1999. A U.S. carbon cycle science plan, a report of the Carbon and Climate Working Group to the United States Global Change Research Program. U.S. Global Change Research Program, Washington, DC.

Shaw, R.H., and U. Schumann. 1992. Large-eddy simulations of turbulent flow above and within a forest. Boundary-Layer Meteorol. 61:47-64.

Shen, S.H., and M.Y. Leclerc. 1997. Modelling the turbulence structure in the canopy layer. Agric. For. Meteorol. 87:3-25.

Siqueira, M., and G.G. Katul. 2002. Estimating heat sources and fluxes in thermally stratified canopy flows using higher-order closure models. Boundary-Layer Meteorol. 103:125-142.

Siqueira, M., C.T. Lai, and G.G. Katul. 2000. Estimating scalar sources, sinks, and fluxes in a forest canopy using Lagrangian, Eulerian, and hybrid inverse models. J. Geophys. Res. 105:29475-29488.

Valentini, R., G. Matteucci, and A.J. Dolman. 2000. Respiration as the main determinant of carbon balance in European forests. Nature 404:861-864.

Van den Hurk, B.J.J.M., and K.G. McNaughton. 1995. Implementation of near-field dispersion in a simple two-layer surface resistance model. J. Hydrol. 166:293-311.

Warland, J.S., and G.W. Thurtell. 2000. A Lagrangian solution to the relationship between a distributed source and concentration profile. Boundary-Layer Meteorol. 96:453-471.

Wilson, J.D. 1988. A second order closure model for flow through vegetation. Boundary-Layer Meteorol. 42:371-392.

Wilson, J.D. 1989. Turbulent transport within the plant canopy. p. 43-80. In T.A. Black et al. (ed.) Estimation of areal evapotranspiration. IAHS Publ. no. 177. IAHS, Wallingford, Oxfordshire, UK.

Wilson, N.R., and R.H. Shaw. 1977. A higher order closure model for canopy flow. J. Appl. Meteorol. 16:1198-1205.

Wofsy, S.C., M.L. Goulden, J.W. Munger, S.M. Fan, P.S. Bakwin, B.C. Daube, S.L. Bassow, and F.A. Bazzaz. 1993. Net exchange of $\mathrm{CO}_{2}$ in a mid-latitude forest. Science 260:1314-1317. 